\title{
Maternal vitamin D status affects bone growth in early childhood-a prospective cohort study
}

\author{
H. T. Viljakainen - T. Korhonen • T. Hytinantti • \\ E. K. A. Laitinen • S. Andersson • O. Mäkitie • \\ C. Lamberg-Allardt
}

Received: 30 June 2010 / Accepted: 25 October 2010 /Published online: 10 December 2010

(C) The Author(s) 2010. This article is published with open access at Springerlink.com

\author{
Abstract \\ Summary In this prospective study, 87 children were \\ followed up from birth to 14 months with data on maternal \\ vitamin D status during the pregnancy. Postnatal vitamin D \\ supplementation improved vitamin D status but only partly \\ eliminated the differences in bone variables induced by \\ maternal vitamin D status during the fetal period. \\ Introduction Intrauterine nutritional deficits may have \\ permanent consequences despite improved nutritional status \\ postnatally. We evaluated the role of prenatal and postnatal \\ vitamin D status on bone parameters in early infancy. \\ H. T. Viljakainen $(\bowtie) \cdot$ T. Hytinantti $\cdot S$. Andersson $\cdot$ O. Mäkitie \\ Hospital for Children and Adolescents, \\ Helsinki University Central Hospital, \\ Tukholmankatu 2C, PO Box 705, 00029, Helsinki, Finland \\ e-mail: heli.viljakainen@helsinki.fi \\ T. Hytinantti \\ e-mail: timo.hytinantti@hus.fi \\ S. Andersson \\ e-mail: sture.andersson@hus.fi \\ O. Mäkitie \\ e-mail: outi.makitie@helsinki.fi \\ T. Korhonen $\cdot$ C. Lamberg-Allardt \\ Department of Food and Environmental Sciences, \\ University of Helsinki, \\ Helsinki, Finland \\ T. Korhonen \\ e-mail: tuuli.korhonen@helsinki.fi \\ C. Lamberg-Allardt \\ e-mail: christel.lamberg-allardt@helsinki.fi \\ E. K. A. Laitinen \\ Department of Obstetrics and Gynecology, \\ Helsinki University Central Hospital, \\ Helsinki, Finland \\ e-mail: kalevi.laitinen@hus.fi
}

Methods Eighty-seven children were followed from birth to 14 months. Background data were collected with a questionnaire and a 3-day food record. At 14 months bone variables were measured with peripheral computed tomography (pQCT) from the left tibia. Serum 25-OHD and bone turnover markers were determined. Findings were compared with maternal vitamin D status during pregnancy. Results The children were divided into two groups based on vitamin D status during pregnancy. Despite discrepant $\mathrm{S}-25-\mathrm{OHD}$ at baseline (median 36.3 vs. $52.5 \mathrm{nmol} / 1, p<$ 0.001 ), the values at 14 months were similar (63 vs. $66 \mathrm{nmol} / \mathrm{l}, p=0.58$ ) in Low D and High D. Serum 25-OHD increased more in Low D $(p<0.001)$ despite similar total intake of vitamin $\mathrm{D}$ (mean $12.3 \mu \mathrm{g} /$ day). In Low $\mathrm{D}$, tibial bone mineral content (BMC) was lower at birth but BMC gain was greater (multivariate analysis of variance [MANOVA]; $p=0.032$ ) resulting in similar BMC at 14 months in the two groups. In High D, tibial total bone cross-sectional area was higher at baseline; the difference persisted at 14 months (MANOVA; $p=0.068$ ). Bone mineral density (BMD) and $\triangle \mathrm{BMD}$ were similar in the two groups.

Conclusions Postnatal vitamin D supplementation improved vitamin D status but only partly eliminated the differences in bone variables induced by maternal vitamin $\mathrm{D}$ status during the fetal period. Further attention should be paid to improving vitamin D status during pregnancy.

Keywords Bone growth - Development - Maternal vitamin D status $\cdot$ Pediatric $\cdot$ Vitamin D

\section{Introduction}

Poor growth during the fetal period, infancy and early childhood is associated with lower adult bone mass and increased 
fracture risk later in life [1-3]. During the fetal period, it is likely that metabolic and endocrine systems are programmed to allow the fetus to adapt to the in utero environment [4]. Vitamin D is a seco sterol that modifies various biological functions in the body [5], and researchers have identified 37 target organs for vitamin D [5]. Low maternal vitamin D status or inadequate dietary vitamin $\mathrm{D}$ intake during pregnancy predisposes children to asthma and allergic rhinitis [6], diabetes [7], acute lower respiratory infection [8], and impaired bone mass accrual. This is evidenced by smaller bone cross-sectional area (CSA) and bone mineral content (BMC) at birth $[9,10]$ and at 9 years of age [11].

Programming of skeletal growth may occur through growth hormone-IGF-I axis [4, 12], whereas bone quality may be determined by factors related to differentiation of mesenchymal stem cells $[13,14]$. The intrauterine environment strongly affects growth rate in infancy, but may also influence growth in puberty [15]. The extent to which changes in nutrient supply between intrauterine and postnatal periods affect growth and development, per se, has not been well established [4]. The most critical views predict that intrauterine nutritional deficits have permanent consequences and that a newborn's metabolism may not adapt to improved nutritional status; the nutrients may not be utilized efficiently and the risk for disease may be maintained despite improved nutritional status [16]. However, postnatal catch-up occurs in linear growth if the fetal deprivation and its timing and magnitude have not been too critical [17].

Previously the authors of the current study have reported that during the pregnancy, $69 \%$ of the women and $37 \%$ of the newborns at birth were vitamin $\mathrm{D}$ deficient (defined in women as S-25-OHD $<50 \mathrm{nmol} / 1[18,19]$ and in the newborn as $<37.5 \mathrm{nmol} / 1$ [20]). The newborn bone variables were measured with peripheral quantitative computed tomography (pQCT) during the hospital stay. Based on these results, it was concluded that maternal vitamin D status affects bone mineral accrual and influences bone size during the intrauterine period [10].

The present prospective study had two objectives. The first was to follow whether the vitamin D-associated skeletal effects observed at birth persist during the first year of life, and the second was to evaluate the impact of postnatal vitamin D status on bone growth and development in early infancy.

\section{Subjects and methods}

Families $(N=124)$ were initially recruited and assessed between October and December 2007 during their labor visit to the birth hospital. They were invited for a follow-up visit approximately 14 months later, between February and
March 2009. The recruitment of families has been described in detail elsewhere [10]. Only primiparous mothers who were healthy, non-smoking, aged between 20 and 40 years, of Caucasian origin, and had an uneventful, singleton, full-term pregnancy (37-42 weeks) were included. The study protocol was approved by the Ethics Committee of Helsinki University Hospital. All mothers gave their written informed consent in accordance with the Declaration of Helsinki. Maternal vitamin D status was assessed in communal prenatal clinics during the first trimesters as part of normal follow-up. A second, fasting blood sample from the mother was collected 2 days postpartum during the hospital stay between late October and mid-December 2007. At birth, cord blood was obtained from the umbilical vein after cord clamping in 81 subjects. Background data was collected through an extensive questionnaire. Records on pregnancy follow-up and the birth report were obtained, including birth weight, length and head circumference measured by midwifes, and duration of the pregnancy. Birth lengths and weights were transformed into Z-scores using Finnish sex-specific normative data for fetal growth [21]. One newborn and her mother were excluded from the initial analysis due to intrauterine growth retardation.

Eighty-seven (70\%) of the original cohort of 124 families agreed to participate in the follow-up visit. Mothers in families agreed on follow-up tended to be younger $(p<0.1)$, they were more educated $(p=0.09)$ and had smaller family $(p=0.08)$ than non-participants, but there were no differences in any pregnancy outcomes. Before the 14-month visit, the families received an extensive questionnaire concerning the child's health and medical history, sunshine exposure, and use of vitamin supplements. The questionnaire included a 3-day food record. During the study visit, one of the researchers interviewed the family about the child's development, including motor and language skills. Of those who agreed to participate in the follow-up visit, all but three returned the questionnaire.

Anthropometric measurements were obtained for each subject. Height was measured at standing position with a wall-mounted height measuring scale and rounded to the nearest $0.1 \mathrm{~cm}$. Weight was measured while sitting on a scale in light clothing and rounded to the nearest $0.1 \mathrm{~kg}$. Heights were transformed into Z-scores and weights were expressed as height-adjusted weights according to Finnish sex-specific normative data for infants [21]. The newborn bone variables were measured with peripheral computed tomography (pQCT) from the left tibia. A blood sample was obtained for laboratory analyses from all but one child. Local anaesthetical patches (EMLA R; AstraZeneca AB, Södertälje, Sweden) were used to reduce the discomfort of venipuncture.

Dietary intakes were calculated from 3-day food records with Diet32 software (Aivo Oy Finland, Turku, Finland). 
The nutrient contents of the foods was based on the Finnish National Food Composition Database, Fineli, version 2001, maintained by the National Public Health Institute of Finland, Nutrition Unit. The total intake of vitamin D included intake from diet and from supplements.

\section{Laboratory measurements}

Serum 25-OHD was measured with an OCTEIA immunoenzymometric assay (IDS, Bolton, UK). The intra-assay coefficient of variation (CV) was less than $3.9 \%$ and interassay variation (4.5\%). Reproducibility was ensured by adhering to the Vitamin D External Quality Assessment Scheme (DEQAS). EIA results were compared with HPLC results in order to determine the reliability of EIA in measuring $25-\mathrm{OHD}_{2}$ concentration. The results were consistent ( $\left.r=0.751, p<0.001, R^{2}=0.495\right)$; therefore, the EIA results were used throughout the study. Vitamin D status in children was defined as deficient when S-25-OHD was below $37.5 \mathrm{nmol} / 1$, insufficient when it was between 37.6 and $50 \mathrm{nmol} / \mathrm{l}$, and sufficient when it was above $50 \mathrm{nmol} / \mathrm{l}$, according to the published pediatric reference values [20]. In adults, a concentration of at least $80 \mathrm{nmol} / 1$ is considered optimal for multiple health outcomes [22].

Serum bone-specific alkaline phosphatase (S-BALP) was assayed with an OCTEIA Octase BAP immunoenzymometric assay (IDS) in order to characterize bone formation. Samples were diluted 1:5 to meet the standard curve. Intra- and interassay CVs were $6.1 \%$ and $6.7 \%$, respectively. The bone resorption marker, serum active isoform $5 \mathrm{~b}$ of the tartrate-resistant acid phosphatase (STRACP), was determined with a bone TRAP assay (SBA Sciences, Turku, Finland). Intra- and interassay CVs were $1.2 \%$ and $3.0 \%$, respectively.

\section{pQCT bone measurement}

Peripheral bone variables were determined by pQCT from the left tibia. One $2.5-\mathrm{mm}$ slice (voxel size, $0.4 \mathrm{~mm}$ ) at the $20 \%$ site of distal tibia, was measured with a XCT-2000 scanner (Stratec, Pforzheim, Germany) as described previously [10]. Data was analyzed using version 5.50 of the manufacturer's software package, in which the bone contour was analyzed with a single threshold of $180 \mathrm{mg} / \mathrm{cm}^{3}$ for the detection of total bone mineral density (BMD), BMC, and CSA. The long-term CVs for the phantom BMD and CSA were $1.9 \%$ and $1.1 \%, 2.7 \%$ and $0.79 \%$, and $0.50 \%$ and $0.78 \%$ in the total, cortical, and trabecular bone, respectively. Short-term precision (CV\%) was determined with duplicate measurements of five subjects. CVs for the total bone BMD and CSA were $6.0 \%$ and $6.5 \%$, respectively. On this basis, the calculated least significant changes for total bone BMD and CSA were $16.7 \%$ and $18.1 \%$, respectively. Out of all the pQCT measurements at 14 months, $67(78 \%)$ were successful.

\section{Statistical methods}

Statistical analyses were performed with SPSS version 16.0 for Windows (SPSS Inc., Chicago, IL). The two groups were compared using an independent samples $t$-test. Repeated-measures ANOVA was applied to follow 25OHD, BMC, CSA, BMD, BALP and TRACP between baseline and the 14-month visit. These time-points were compared using contrasts. Determinants for bone analysis were identified with Pearson correlations. Where necessary, variables were transformed using logarithms in order to satisfy statistical assumptions of normality. Differences between groups in BMC, CSA and BMD at 14 months, as well as in $\triangle B M C, \triangle C S A$ and $\triangle B M D$ (change from birth to 14 months), were tested with multivariate analysis utilizing the same confounding factors. Results are presented as mean (SD) unless otherwise indicated. Results were considered significant when $p<0.05 ; p$ values between 0.05 and 0.10 were considered trends.

\section{Results}

A total of 87 children ( $57 \%$ boys) were followed up for 14 months. Their mean (SD) values for age, weight, heightadjusted weight, height, and height Z-score were $14.8(0.5)$ months, $10.8(1.3) \mathrm{kg}, 0.68(7.6) \%, 78.6(3.2) \mathrm{cm}$, and 0.11 (1.1), respectively. For data analysis, the participants were divided into two groups based on maternal vitamin $\mathrm{D}$ status during pregnancy. The median maternal S-25-OHD value, $42.6 \mathrm{nmol} / \mathrm{l}$, was used as the cutoff to define two equal-sized groups of children with below-median (=Low D; mean S-25OHD 35.7 [5.0] nmol/l) and above-median (=High D; mean S-25-OHD 54.9 [9.1] nmol/1) maternal S-25-OHD concentration. Table 1 presents the background characteristics of these two groups at baseline and at the 14-month follow-up. The duration of exclusive was similar in groups (see Table 1). Eighteen children $(21.7 \%)$ were still breastfed at the time of the follow-up visit. Dietary intakes of energy, protein, vitamin $\mathrm{D}$ and calcium did not differ between the groups and all children had normal development. Only the age when the children started to walk with support differed between the groups; all other developmental milestones were similar.

Despite lower vitamin D concentration during pregnancy and at birth in Low D than in High D (means 35.7 vs. $54.2 \mathrm{nmol} / 1$, and in the cord 40.5 and $59.3 \mathrm{nmol} / 1$, independent samples $t$-test; $p<0.001$, respectively), the 25 OHD concentrations in the two groups at 14 months were similar (63 vs. $66 \mathrm{nmol} / \mathrm{l}, p=0.58$ ). Serum 25-OHD increased from mean pregnancy value and cord more in 
Table 1 Background characteristics and changes in them from baseline value given as mean (SD)

\begin{tabular}{|c|c|c|c|}
\hline & Low D & High D & Independent samples $t$-test \\
\hline$N$ & 44 & 43 & \\
\hline Age, months & $14.9(0.5)$ & $14.8(0.5)$ & 0.336 \\
\hline Males, \% & 58 & 55 & $0.842^{\mathrm{a}}$ \\
\hline \multicolumn{4}{|l|}{ Anthropometric and growth variables } \\
\hline Weight, $\mathrm{kg}$ & $10.8(1.3)$ & $10.8(1.3)$ & 0.997 \\
\hline Relative weight & $-1.2(8.1)$ & $0.2(6.7)$ & 0.382 \\
\hline$\Delta$ Weight, $\mathrm{kg}$ & $7.1(1.1)$ & $7.2(1.0)$ & 0.624 \\
\hline Weight velocity, g/month & $475(72)$ & $488(67)$ & 0.446 \\
\hline Height, $\mathrm{cm}$ & $79.0(2.8)$ & $78.4(3.5)$ & 0.386 \\
\hline Height Z-score & $0.25(1.0)$ & $0.03(1.2)$ & 0.378 \\
\hline$\Delta$ Height, $\mathrm{cm}$ & $27.9(2.0)$ & $27.7(2.9)$ & 0.732 \\
\hline Height velocity, $\mathrm{cm} /$ month & $1.88(0.12)$ & $1.87(0.19)$ & 0.951 \\
\hline \multicolumn{4}{|l|}{ History of breast feeding and dietary intakes } \\
\hline Duration of exclusive breastfeeding, months & $4.2(1.9)$ & $4.3(2.0)$ & 0.755 \\
\hline Currently breastfed, $N(\%)$ & $11(26.8)$ & $7(16.6)$ & $0.196^{\mathrm{a}}$ \\
\hline Energy intake, kcal/day & $920(220)$ & $930(180)$ & 0.770 \\
\hline Fat intake, g/day & $28.6(7.9)$ & $28.0(6.9)$ & 0.698 \\
\hline Protein intake, $g$ /day & $43(13)$ & $42(10)$ & 0.481 \\
\hline Calcium intake, mg/day & $820(320)$ & $840(260)$ & 0.863 \\
\hline Total intake of vitamin $\mathrm{D}, \mu \mathrm{g} /$ day & $12.4(3.1)$ & $12.2(2.9)$ & 0.782 \\
\hline \multicolumn{4}{|l|}{ Motor and language skills } \\
\hline Age when learnt to crawl, months & $8.0(1.8)$ & $8.2(1.8)$ & 0.690 \\
\hline Age when learnt to stand, months & $8.4(1.7)$ & $8.5(1.6)$ & 0.668 \\
\hline Age when learnt to walk with support, months & $8.8(1.6)$ & $10.1(1.5)$ & 0.001 \\
\hline Age when learnt to walk without support, months & $11.9(1.6)$ & $12.1(1.5)$ & 0.458 \\
\hline Number of words in use & $5.7(6.2)$ & $6.8(7.7)$ & 0.490 \\
\hline
\end{tabular}

${ }^{\mathrm{a}}$ Pearson chi square

Low D than it did in High D (28 vs. $10 \mathrm{nmol} / 1$ and 23.6 vs. $6 \mathrm{nmol} / \mathrm{l}$, respectively; independent samples $t$-test; $p<$ 0.001 ), although the total intake of vitamin D was similar, at an average of $12.3(3.0) \mu \mathrm{g} /$ day (Table 2). The total intake of vitamin D correlated positively with 25-OHD concentration in the whole cohort $(r=0.301, p=0.005)$ and in High D $(r=0.505, p<0.001)$, but not in Low D $(r=0.219$, $p=0.168$ ) (Fig. 1). Vitamin D status according to several reference values $[20,22]$ did not differ between the groups. Of the total cohort, $21 \%, 62 \%$ and $17 \%$ had S-25-OHD below $50 \mathrm{nmol} / 1$, between 50 and $79.9 \mathrm{nmol} / 1$ or at least $80 \mathrm{nmol} / \mathrm{l}$, respectively (Table 3 ). Higher dietary intake of vitamin $\mathrm{D}$ and use of $\mathrm{D}_{3}$ supplements were related to improved vitamin D status.

\section{Tibia BMC, CSA and BMD}

Bone measurements were successful in 68 of subjects (78\%) at the 14-month visit. For the longitudinal bone analysis, complete baseline and follow-up data were available for 29 subjects in
Low D and 26 subjects in High D. Determinants of bone variables were gender, birth weight Z-score, walking age, duration of exclusive breastfeeding and S-25-OHD at 14 months. At the 14-month visit, boys had a higher BMC, $\triangle \mathrm{BMC}$ and BMD than girls (independent samples $t$-test; $p=$ $0.002, p=0.002$ and $p=0.02$, respectively). Birth weight Zscore correlated strongly with $\mathrm{BMC}$ and CSA at 14 months ( $r=0.507, p<0.001$ and $r=0.368, p=0.004$ ). Similarly, walking age was inversely associated with BMC, CSA and S-25-OHD at 14 months $(r=-0.545, p<0.001, r=-0.433, p<0.001$, and $r=-0.194, p=0.083$, respectively). The duration of exclusive breastfeeding correlated negatively with BMC, $\triangle \mathrm{BMC}$, CSA and $\Delta$ CSA ( $r$ varying from -0.377 to $-0.428, p=0.002$ ). S- 25 $\mathrm{OHD}$ at the 14-month visit was only modestly related to BMD and $\triangle$ BMD $(r=-0.230, p=0.08$ and $r=-0.142, p=0.250)$, but was included in the model as well.

The development of BMC from baseline to 14 months differed between the groups (repeated-measures multivariate analysis of variance [MANOVA]; $p=0.023$ ) (Fig. 2a) due to greater baseline BMC in High D. However, the total BMC 
Table 2 Biochemical markers at 14-month visit and changes in them from baseline value given as mean (SD)

\begin{tabular}{|c|c|c|c|}
\hline & Low D & High D & Independent samples $t$-test \\
\hline$N$ & 46 & 40 & \\
\hline Mean of first trimester and postpartum maternal $25-\mathrm{OHD}, \mathrm{nmol} / \mathrm{l}$ & $35.7(5.0)$ & $54.2(9.1)$ & $<0.001$ \\
\hline Cord 25-OHD, nmol/1 & $40.3(7.2)$ & $59.5(12.2)$ & $<0.001$ \\
\hline At 14-month S-25-OHD, nmol/1 & $63.0(20.7)$ & $65.6(21.2)$ & 0.575 \\
\hline $\mathrm{S}-25-\mathrm{OHD}_{3} /$ total $25-\mathrm{OHD}^{\mathrm{a}}$ & $0.50(0.28)$ & $0.50(0.24)$ & 0.878 \\
\hline$\Delta \mathrm{S}-25-\mathrm{OHD}^{\mathrm{b}}, \mathrm{nmol} / \mathrm{l}$ & $27.5(22.2)$ & $10.2(19.4)$ & 0.001 \\
\hline$\Delta \mathrm{S}-25-\mathrm{OHD}^{\mathrm{c}}, \mathrm{nmol} / \mathrm{l}$ & $23.0(23.2)$ & $6.0(22.1)$ & 0.002 \\
\hline S-TRACP, U/1 & $11.2(4.0)$ & $10.0(4.1)$ & 0.199 \\
\hline$\Delta \mathrm{S}$-TRACP, U/1 & $-0.28(4.3)$ & $-0.47(4.7)$ & 0.876 \\
\hline S-BALP, $\mu \mathrm{g} / 1$ & $124(38)$ & $122(38)$ & 0.847 \\
\hline$\Delta \mathrm{S}-\mathrm{BALP}, \mu \mathrm{g} / \mathrm{l}$ & $69.2(37.4)$ & $62.4(42.8)$ & 0.527 \\
\hline
\end{tabular}

${ }^{a}$ Based on HPLC

${ }^{\mathrm{b}}$ An increment of S-25-OHD from mean maternal to 14-month visit

${ }^{\mathrm{c}}$ An increment of S-25-OHD from cord to 14-month visit; $N=30, N=31$

gain $\left(\triangle \mathrm{BMC}=\mathrm{BMC}_{14}\right.$ month $\left.-\mathrm{BMC}_{\text {baseline }}\right)$ during the first year was $0.062(\mathrm{SEM}=0.029) \mathrm{g} / \mathrm{cm}$ greater in Low $\mathrm{D}$ (MANOVA; $p=0.032$ ); consequently, no difference was observed in BMC between the groups at the 14-month visit. TB CSA from baseline to the 14-month visit was significantly higher in High D than in Low D (repeated MANOVA; $p=0.004$ ) (Fig. 2b) due to the higher baseline CSA in High D. $\triangle \mathrm{CSA}$ did not differ between the groups. Thus, a trend to higher CSA at 14 months by $14.6(\mathrm{SEM}=7.8) \mathrm{mm}^{2}$ (MANOVA; $p=0.068$ ) remained in High D. There was no difference between the groups in BMD during the 14 months (Fig. 2c) or in $\triangle \mathrm{BMD}$. The observed decrease in BMD is a consequence of a greater increment in CSA compared with the gain in $\mathrm{BMC}(69 \%$ vs. $18 \%)$.

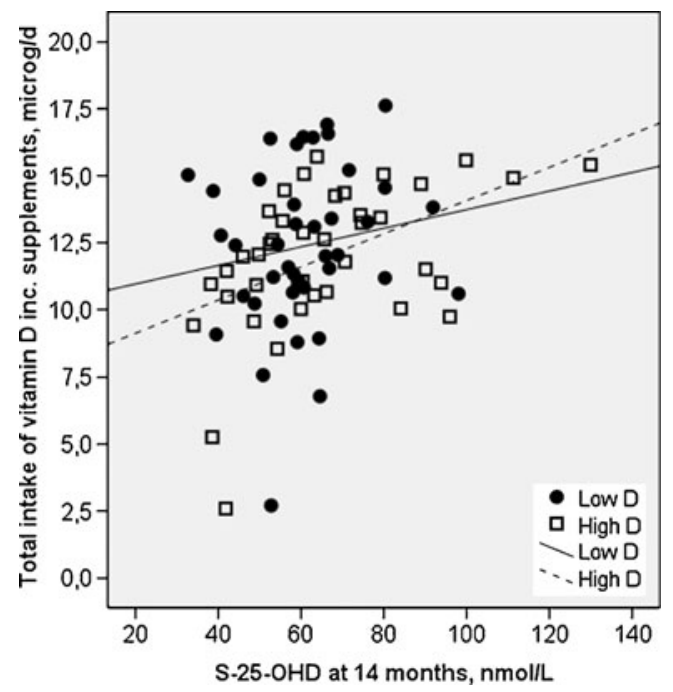

Fig. 1 Total intake of vitamin D correlated positively with serum 25 OHD in High D $(r=0.505, p<0.001)$, but not in Low D $(r=0.219, p=$ 0.168). Squares indicate High D and circles indicate Low D
Bone turnover markers

BALP, a surrogate of bone formation, increased dramatically from baseline (repeated measures MANOVA; $p<0.001$ ) (Fig. 3a), while TRACP concentration remained at the same level during the 14 months (Fig. 3b). At the 14-month visit, TRACP, BALP, or their ratio did not differ between the groups. There was no correlation between BALP and TRACP, but $\triangle$ TRACP correlated positively with $\Delta 25$ $\mathrm{OHD}\left(=25-\mathrm{OHD}_{14}\right.$ month $\left.-25-\mathrm{OHD}_{\text {pregnancy mean }}\right)(r=0.345$, $p=0.012)$. Correspondingly, $\triangle \mathrm{BALP}$ correlated inversely with $\Delta 25$-OHD $(r=-0.213, p=0.034)$. The correlations were similar in both groups.

\section{Discussion}

This prospective study made three key findings. Firstly, distal tibia CSA remained larger at 14 months in infants with higher maternal vitamin $\mathrm{D}$ status during pregnancy than in infants with lower maternal vitamin D status. Secondly, the increment in tibial BMC from birth to 14 months was higher in those with inferior maternal vitamin $\mathrm{D}$ status during pregnancy. This resulted in similar BMC and BMD at 14 months in both study groups. Finally, $20 \%$ of the children had S-25-OHD below $50 \mathrm{nmol} / 1$ at 14 months of age, although their median total intake of vitamin D was $12.2(3.0) \mu \mathrm{g}$, which meets the Nordic recommendation for this age group [23].

Other interesting findings related to bone growth in this prospective cohort were that boys had higher BMC, and $\mathrm{BMC}$ increased more during the 14 months and resulted in higher volumetric BMD in distal tibia than in girls. Children in high vitamin D group learnt to walk with support later than children in low vitamin D group, 
Table 3 Distribution of vitamin D status in 1-year-old children and mean intake in each category

\begin{tabular}{llll}
\hline $\begin{array}{l}\text { S-25-OHD } \\
(\mathrm{nmol} / \mathrm{l})\end{array}$ & $N(\%)$ & $\begin{array}{l}\text { Total intake of } \\
\text { vitamin } \mathrm{D}(\mu \mathrm{g} / \text { day })^{\mathrm{a}}\end{array}$ & $\begin{array}{l}\text { User of } \mathrm{D}_{2} \\
(\%)^{\mathrm{b}}\end{array}$ \\
\hline$<37.5$ & $2(2.3)$ & $12.2(4.0)$ & 100 \\
$37.6-50$ & $16(18.6)$ & $10.6(3.1)$ & 100 \\
$50.1-79.9$ & $53(61.6)$ & $12.4(2.8)$ & 88.5 \\
$\geq 80$ & $15(17.4)$ & $13.1(2.5)$ & 50 \\
Total $(\mathrm{N})$ & 86 & 84 & 84 \\
\hline
\end{tabular}

${ }^{\mathrm{a}}$ Total intake differed between categories of 25-OHD (ANOVA; $p=0.03$ )

${ }^{\mathrm{b}}$ Distribution of $\mathrm{D}_{2}$ users differed between categories (chi square; $p=$ $0.001)$

although other developmental milestones were similar. We consider this as a random finding because it is unlikely that higher maternal vitamin D status would contribute to this and several studies have witnessed that vitamin D deficiency is related to delayed age of walking $[24,25]$. In this study, walking age without support was inversely related to tibia BMC and CSA, suggesting that earlier walking enhances bone development. Similarly jumping is shown increase the outer diameter of the tibia in a randomized controlled trial of 3- to 5-year-old children [26]. Walking is one of the first weight-bearing exercises modifying the strength of the tibia, but it is unsure if the association between walking age and bone health will preserve in the future. Surprisingly, longer exclusive breastfeeding was linked to lower bone development, which might be a sum of prolonged growth rate [27] and possible lower intakes of nutrients. However, infant 25-OHD at 14-month visit was only modestly related to bone growth; thus, it was included as a confounder in the model.
Maternal vitamin D status regulates skeletal growth and development during fetal life $[9,10,28]$. The present study proves that these effects partly persist in early childhood, as has been suggested in a longer prospective study [11]. Tibia CSA remained somewhat larger in infants whose mothers had better vitamin D status during pregnancy. Besides genetic background bone size is affected by various hormones and it has been shown that growth hormoneIGF-1 axis is responsible for bone size [29] and periosteal expansion [30, 31]. Leptin may favor stem cell differentiation towards osteoblasts rather than adipocytes [32] in infancy. Furthermore, vitamin D stimulates osteoblastogenesis in human mesenchymal stem cells and production of IGF-1 in osteoblasts [14]. In infants with rickets vitamin D supplementation increases serum IGF-1 and accelerates linear growth [33]. In this study, we did not measure IGF-1 and other growth hormone parameters, but height and weight velocities did not differ between the groups. Although all infants received vitamin D supplementation, the difference between the groups in tibia CSA was maintained until 14 months of age. The difference at birth was $16 \%$ and $11 \%$ at 14 months. This shows that the fetal bone growth tracks during the first year [34], which emphasizes the meaning of maternal nutrition for bone trajectory. Bone size is a major determinant of bone strength [35] and therefore the observed differences in CSA may have significant clinical implications in fracture resistance.

Unlike CSA, BMC or BMD did not differ between the study groups at the 14-month visit. This is explained by the steep increment of BMC in Low D group. In fact, the BMC accrual was about three times higher in Low D than in High D $(28.7 \%$ vs. $8.4 \%)$, and due to this catch-up in Low D there was no difference in distal tibia BMC between the groups at 14 months. The greater increase in BMC in Low
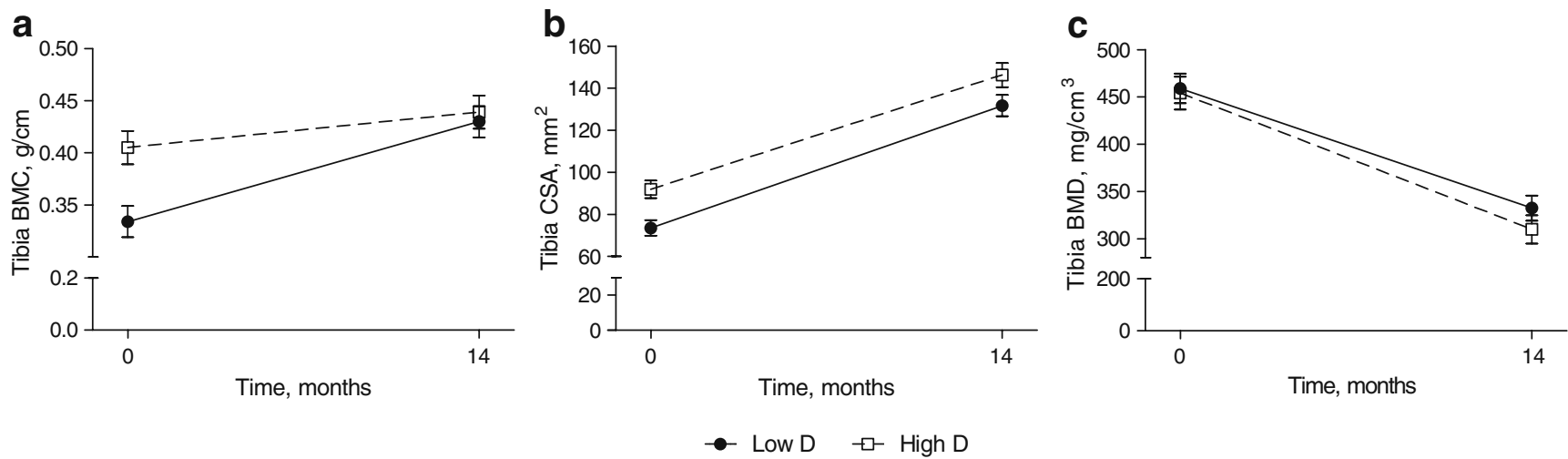

Fig. 2 BMC, CSA and BMD in study groups from baseline to 14 months. Increase in BMC from baseline to 14 months differed between the groups (repeated-measures MANOVA; $p=0.023$ ) (a) due to higher baseline BMC in High D. No difference was observed in BMC between the groups at the 14-month visit. TB CSA from baseline to 14 months was significantly higher in High D than in Low
D (repeated-measures MANOVA; $p=0.004$ ) (b) due to the higher baseline CSA in High D. At 14 months, CSA remained 14.6 (SEM= 7.8) $\mathrm{mm}^{2}$ (MANOVA; $p=0.068$ ) higher in High D. There was no difference between the groups in BMD during the 14 months (c) or in $\triangle \mathrm{BMD}$. Low D and High D groups are represented by circles and squares, respectively. Error bars represent SEMs 
a

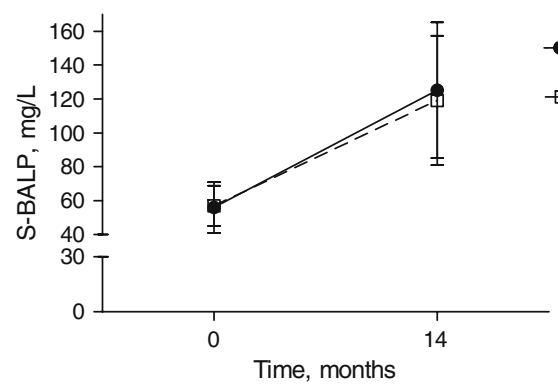

Fig. 3 Concentrations of BALP and TRACP in study groups from baseline to 14 months. Low D and High D are represented by circles and squares, respectively. Error bars represent SEM. BALP increased b

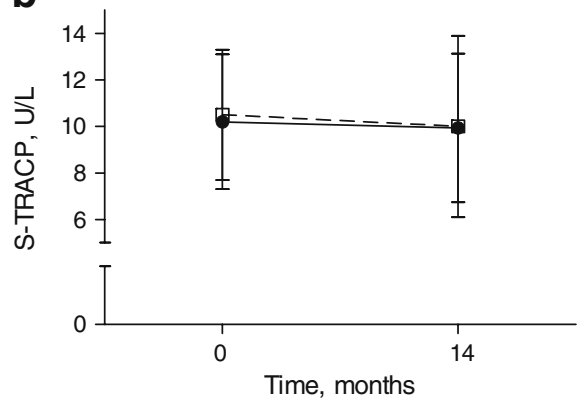

from baseline (repeated-measures MANOVA; $\mathrm{p}<0.001$ ) (a) while TRACP concentration remained at the same level during the 14 months (b). There were no differences between the study groups
D group is likely to be due to increased calcium accrual, as reverted vitamin D status enhances calcium absorption. Some studies have witnessed that insufficient vitamin D status during pregnancy is related to lower bone mineral status in the newborn $[9,10,28]$. Initially, $70 \%$ of the mothers were vitamin $\mathrm{D}$ deficient during the pregnancy as their mean serum 25-OHD for first trimester and 2 days postpartum was less than $50 \mathrm{nmol} / 1$. Improved postnatal vitamin $\mathrm{D}$ status results in catch-up in BMC, but not in CSA. Decline in BMD was similar in both study groups and it reflects a redistribution of bone tissue from the endocortical to the periosteal surface. An explanation for declined BMD might be that cortical thickness decreased during the 14 months while the amount of trabecular bone increased [36].

In early infancy, peripheral bones grow by increasing the outer diameter rather than the mineral content [36]. In the whole group tibia CSA increased dramatically (68\%), indicating that the periosteal diameter and circumference increased. The growth in periosteal circumference occurred similarly in groups, but High D group started at a higher level and hence stayed higher at 14-month visit.

Vitamin D supplementation is recommended for all infants aged between 2 weeks and 3 years in Nordic countries in order to guarantee a total intake of $10 \mu \mathrm{g} /$ day. All subjects in the present study received supplementation, compared to a representative study cohort in Finland, in which $85 \%$ of 1 -year-old infants and $70 \%$ of 2 -year-old infants were reported to receive vitamin D supplementation [37]. Thus, families in the present study were somewhat selected and possibly more health-orientated than the Finnish population in general. In the present study, $85 \%$ of infants had total vitamin D intake that was in line with the Nordic recommendation [23]. Interestingly, the use of $\mathrm{D}_{3}$ supplements was associated with improved vitamin D status to a greater extent than use of $\mathrm{D}_{2}$ supplements, which is in line with findings of Houghton and Vieth [38]. However, the number of $\mathrm{D}_{3}$ users was very low $(N=12)$, which means that further comparison between different forms of vitamin D is not justified. Because of vitamin D supplementation, S-25-OHD concentration increased during the follow-up. Interestingly, the increase was higher in group with inferior S-25-OHD during pregnancy than in group with higher 25-OHD during pregnancy ( $\Delta$ S-25-OHD 27.5 vs. $10.2 \mathrm{nmol} / \mathrm{l})$. In line with earlier findings [39, 40], a higher response was observed in those with initially lower status. However, neither S-25-OHD nor $\triangle \mathrm{S}-25-\mathrm{OHD}$ was significantly associated with pQCT bone variables at 14 months or their changes during the 14-month follow-up. The study shows that fetal vitamin D status, rather than postnatal vitamin $\mathrm{D}$ status, affects bone growth during the first year. On the other hand, S-25-OHD reflects relatively short-term accumulation of dietary vitamin D and solar exposure [41], whereas observing differences in bone variables takes more time. $\triangle \mathrm{S}-25-\mathrm{OHD}$ correlated positively with $\triangle \mathrm{S}$-TRACP and inversely with $\triangle \mathrm{BALP}$ suggesting that vitamin $\mathrm{D}$ affects bone turnover [42]. Consequently, S-25-OHD may be a significant determinant of bone turnover in infants, although growth, diet and motor development also play a part.

There was a positive association between total intake of vitamin D and 25-OHD in the entire group and in High D, but not among those infants in Low D whose vitamin D status during pregnancy was worse. At the 14-month visit, $2.3 \%, 18.4 \%$ and $79.3 \%$ were defined as vitamin D deficient, insufficient and sufficient, respectively [20]. Given that more than $20 \%$ of the infants had S-25-OHD below $50 \mathrm{nmol} / \mathrm{L}$, despite compliance with supplementation, higher intake of vitamin $\mathrm{D}$ is recommended in order to obtain all the potential health benefits of vitamin D [43, 44]. Optimally, vitamin D sufficiency should be guaranteed during fetal life as the findings of the present study suggest that the consequences of poor vitamin D status during the fetal period cannot be totally reverted by postnatal vitamin D supplementation.

One of the limitations of the study was that only $70 \%$ of the families were willing to attend the 14-month follow-up 
visit. Furthermore, only $78 \%$ of the pQCT measurements at 14 months were successful, which resulted in problems with the sample size in data analysis. A sample size of 35 per group would have been required in order to reach sufficient statistical power. Only total bone parameters were measured with pQCT from the $20 \%$ site of tibia. This site contains both cortical and trabecular bone, but we did not quantify those separately because the cortical thickness is relatively small compared to voxel size and partial volume effect obscured the results. However, the strength of this study was a prospective study design with antenatal vitamin D status.

It can be concluded that postnatal vitamin D supplementation improved vitamin D status in infants and partly eliminated the differences in bone variables that had resulted from maternal vitamin $\mathrm{D}$ status during the fetal period. The difference remained in total bone CSA, while it disappeared in BMC. It seems unlikely, therefore, that improving vitamin $\mathrm{D}$ intake merely in infancy would revert the consequences of poor vitamin D status during the fetal period. Based on these observations, additional efforts should be made to improve vitamin D status during pregnancy.

Acknowledgements The authors (indicated by their initials) contributed to the study as follows: HTV was involved in the planning of this study, and was responsible for organizing the study visits, data collection, measurement of bone mineral densities, laboratory measurements, statistical analyses and writing the manuscript. TK participated in study visits and was responsible for data collection, data coding and analysis of pQCT scans. TH and EKAL participated in the planning of this study and review of the manuscript. SA, OM and CLA were likewise involved in planning this study, helped in securing financial support for this work and reviewed the manuscript.

\section{Conflicts of interest None.}

Open Access This article is distributed under the terms of the Creative Commons Attribution Noncommercial License which permits any noncommercial use, distribution, and reproduction in any medium, provided the original author(s) and source are credited.

\section{References}

1. Cooper C, Fall C, Egger P, Hobbs R, Eastell R, Barker D (1997) Growth in infancy and bone mass in later life. Ann Rheum Dis 56:17-21

2. Yarbrough DE, Barrett-Connor E, Morton DJ (2000) Birth weight as a predictor of adult bone mass in postmenopausal women: the Rancho Bernardo Study. Osteoporos Int 11:626-630

3. Cooper C, Eriksson JG, Forsén T, Osmond C, Tuomilehto J, Barker DJ (2001) Maternal height, childhood growth and risk of hip fracture in later life: a longitudinal study. Osteoporos Int 12:623-629

4. Jansson T, Powell TL (2007) Role of the placenta in fetal programming: underlying mechanisms and potential interventional approaches. Clin Sci (Lond) 113:1-13
5. Norman AW (2008) A vitamin D nutritional cornucopia: new insights concerning the serum 25-hydroxyvitamin D status of the US population. Am J Clin Nutr 88:1455-1456

6. Erkkola M, Kaila M, Nwaru BI et al (2009) Maternal vitamin D intake during pregnancy is inversely associated with asthma and allergic rhinitis in 5-year-old children. Clin Exp Allergy 39:875882

7. Stene LC, Ulriksen J, Magnus P, Joner G (2000) Use of cod liver oil during pregnancy associated with lower risk of Type I diabetes in the offspring. Diabetologia 43:1093-1098

8. Karatekin G, Kaya A, Salihoğlu O, Balci H, Nuhoğlu A (2009) Association of subclinical vitamin D deficiency in newborns with acute lower respiratory infection and their mothers. Eur J Clin Nutr 63:473-477

9. Weiler H, Fitzpatrick-Wong S, Veitch R et al (2005) Vitamin D deficiency and whole-body and femur bone mass relative to weight in healthy newborns. CMAJ 172:757-761

10. Viljakainen HT, Saarnio E, Hytinantti T et al (2010) Maternal vitamin D status determines bone variables in the newborn. J Clin Endocrinol Metab 95:1749-1757

11. Javaid MK, Crozier SR, Harvey NC et al (2006) Maternal vitamin D status during pregnancy and childhood bone mass at age 9 years: a longitudinal study. Lancet 367:36-43

12. Wells JC, Chomtho S, Fewtrell MS (2007) Programming of body composition by early growth and nutrition. Proc Nutr Soc 66:423434

13. Lanham SA, Roberts C, Cooper C, Oreffo RO (2008) Intrauterine programming of bone: Part 1. alteration of the osteogenic environment. Osteoporos Int 19:147-156

14. Zhou S, LeBoff MS, Glowacki J (2010) Vitamin D metabolism and action in human bone marrow stromal cells. Endocrinology $151: 14-22$

15. Neave N, Laing S, Fink B, Manning JT (2003) Second to fourth digit ratio, testosterone and perceived male dominance. Proc Biol Sci 270:2167-2172

16. Gluckman PD, Hanson MA (2004) The developmental origins of the metabolic syndrome. Trends Endocrinol Metab 5:183-187

17. Tanner JM (1989) The organisation of the growth process. In: Foetus into man: Physical growth from conception to maturity, 2nd edn. Castlemead Publications, Ware, England, pp 165-177

18. Rizzoli R, Boonen S, Brandi ML, Burlet N, Delmas P, Reginster JY (2008) The role of calcium and vitamin D in the management of osteoporosis. Bone 42:246-249

19. Lips P, Bouillon R, van Schoor NM et al (2009) Reducing fracture risk with calcium and vitamin D. Clin Endocrinol (Oxf) 10: [Epub ahead of print] PubMed PMID: 19744099

20. Misra M, Pacaud D, Petryk A, Collett-Solberg PF, Kappy M, Drug and Therapeutics Committee of the Lawson Wilkins Pediatric Endocrine Society (2008) Vitamin D deficiency in children and its management: review of current knowledge and recommendations. Pediatrics 122:398-417

21. Pihkala J, Hakala T, Voutilainen P, Raivio K (1989) Characteristic of recent fetal growth curves in Finland. Duodecim 105:1540-1546

22. Bischoff-Ferrari HA, Giovannucci E, Willett WC, Dietrich T, Dawson-Hughes B (2006) Estimation of optimal serum concentrations of 25-hydroxyvitamin D for multiple health outcomes. Am J Clin Nutr 84:18-28

23. Nordic Council of Ministers. Nordic Nutrition Recommendations (2004) Integrating nutrition and physical activity, 4th edn. Nord, Copenhagen, 13

24. Thacher TD, Fischer PR, Pettifor JM, Lawson JO, Isichei CO, Chan GM (2000) Case-control study of factors associated with nutritional rickets in Nigerian children. J Pediatr 137:367-373

25. Agarwal A, Gulati D, Rath S, Walia M (2009) Rickets: a cause of delayed walking in toddlers. Indian J Pediatr 76:269-272 
26. Specker B, Binkley T (2003) Randomized trial of physical activity and calcium supplementation on bone mineral content in 3- to 5year-old children. J Bone Miner Res 18:885-892

27. Hediger ML, Overpeck MD, Ruan WJ, Troendle JF (2000) Early infant feeding and growth status of US-born infants and children aged 4-71 mo: analyses from the third National Health and Nutrition Examination Survey, 1988-1994. Am J Clin Nutr 72:159-167

28. Salle BL, Delvin EE, Lapillonne A, Bishop NJ, Glorieux FH (2000) Perinatal metabolism of vitamin D. Am J Clin Nutr 71(5 Suppl):1317S-1324S

29. Javaid MK, Godfrey KM, Taylor P et al (2004) Umbilical venous IGF-1 concentration, neonatal bone mass, and body composition. J Bone Miner Res 19:56-63

30. Bourrin S, Ammann P, Bonjour JP, Rizzoli R (2000) Dietary protein restriction lowers plasma insulin-like growth factor I (IGF-I), impairs cortical bone formation, and induces osteoblastic resistance to IGF-I in adult female rats. Endocrinology 141:3149-3155

31. Ammann P, Shen V, Robin B, Mauras Y, Bonjour JP, Rizzoli R (2004) Strontium ranelate improves bone resistance by increasing bone mass and improving architecture in intact female rats. J Bone Miner Res 19:2012-2020

32. Thomas T, Gori F, Khosla S, Jensen MD, Burguera B, Riggs BL (1999) Leptin acts on human marrow stromal cells to enhance differentiation to osteoblasts and to inhibit differentiation to adipocytes. Endocrinology 140:1630-1638

33. Soliman AT, Al Khalaf F, Alhemaidi N, Al Ali M, Al Zyoud M, Yakoot K (2008) Linear growth in relation to the circulating concentrations of insulin-like growth factor I, parathyroid hormone, and 25-hydroxy vitamin $\mathrm{D}$ in children with nutritional rickets before and after treatment: endocrine adaptation to vitamin D deficiency. Metabolism 57:95-102
34. Harvey N, Mahon P, Robinson S et al (2009) Different indices of fetal growth predict bone size and volumetric density at 4 years old. J Bone Miner Res 19. Epub ahead of print, PubMed PMID: 19839768

35. Szulc P (2006) Bone density, geometry, and fracture in elderly men. Curr Osteoporos Rep 4:57-63

36. Rauch F, Schoenau E (2001) Changes in bone density during childhood and adolescence: an approach based on bone's biological organization. J Bone Miner Res 16:597-604

37. Kyttälä P, Ovaskainen M, Kronberg-Kippilä C et al (2008) Lapsen ruokavalio ennen kouluikää, The Diet of Finnish Preschoolers. Kansanterveyslaitoksen julkaisuja B 32/2008

38. Houghton LA, Vieth R (2006) The case against ergocalciferol (vitamin $\mathrm{D}_{2}$ ) as a vitamin supplement. Am J Clin Nutr 84:694-697

39. Heaney RP, Davies KM, Chen TC, Holick MF, Barger-Lux MJ (2003) Human serum 25-hydroxy-cholecalciferol response to extended oral dosing with cholecalciferol. Am J Clin Nutr 77:204-210

40. Viljakainen HT, Palssa A, Kärkkäinen M, Jakobsen J, LambergAllardt C (2006) How much vitamin $\mathrm{D}_{3}$ do the elderly need? J Am Coll Nutr 25:429-435

41. Millen AE, Bodnar LM (2008) Vitamin D assessment in population based studies: a review of the issues. Am J Clin Nutr 87:1102S-1105S

42. Gurlek A, Pittelkow MR, Kumar R (2002) Modulation of growth factor/cytokine synthesis and signaling by 1,25 -dihydroxyvitamin $\mathrm{D}(3)$ : implications in cell growth and differentiation. Endocr Rev 23:763-786

43. Litonjua AA, Weiss ST (2007) Is vitamin D deficiency to blame for the asthma epidemic? J Allergy Clin Immunol 120:1031-1035

44. Lapillonne A (2010) Vitamin D deficiency during pregnancy may impair maternal and fetal outcomes. Med Hypotheses 74:71-75 